\title{
The Moderating Role of Classroom Descriptive Norms in the Association of Student Behavior With Social Preference and Popularity
}

Journal of Early Adolescence 2017, Vol. 37(3) 387-413

(C) The Author(s) 2015

Reprints and permissions: sagepub.com/journalsPermissions.nav DOI: $10.1177 / 0272431615609158$ journals.sagepub.com/home/jea

@SAGE

\section{Henrike J. Boor-Klip', Eliane Segers', Marloes M. H. G. Hendrickx², and Antonius H. N. Cillessen'}

\begin{abstract}
This study addressed the moderating role of classroom descriptive norms for overt and relational aggression, social withdrawal, prosocial behavior, and academic reputation in the association of behavior with social preference and popularity in early adolescence. Participants were I,492 fifth-grade students $\left(\bar{X}_{\text {age }}=10.6\right.$ years, $52.7 \%$ boys $)$ from 59 classrooms who completed unlimited peer nominations for status and behavior. Classroom descriptive norms were computed as the average proportion of classroom nominations received for the different social behaviors. Multilevel analyses revealed that the negative association between overt aggression and social preference was attenuated in classrooms with high norms for overt aggression. The negative association between academic reputation and social preference was enhanced in classrooms with high norms for academic reputation. Classroom norms did not moderate the associations between behavior and popularity. The type of behavior and the type of status should be considered when examining classroom descriptive norms and behavior-status associations.
\end{abstract}

\footnotetext{
'Radboud University, Nijmegen, The Netherlands

2Utrecht University, The Netherlands

\section{Corresponding Author:}

Henrike J. Boor-Klip, Behavioural Science Institute, Radboud University, Montessorilaan 3, 6525 HR Nijmegen, The Netherlands.

Email: h.klip@psych.ru.nl
} 


\section{Keywords}

classroom norms, social preference, popularity, student behavior, early adolescence

In early adolescence, it is a priority of many students to have a high social status among their classroom peers (LaFontana \& Cillessen, 2010; Rubin, Bukowski, \& Parker, 2006). Student behavior (e.g., aggression or prosocial behavior) is an important factor that contributes to social status (e.g., Asher \& McDonald, 2009; Cillessen \& Mayeux, 2004; Lease, Musgrove, \& Axelrod, 2002; Newcomb, Bukoswki, \& Pattee, 1993). However, contextual factors may moderate the link between student behavior and social status (e.g., Becker \& Luthar, 2007; Mikami, Lerner, \& Lun, 2010). That is, in some contexts, the association between behavior and social status may be strong, whereas it may be moderate or even absent in other contexts.

A key contextual moderator of the association between student behavior and social status is the classroom descriptive norm of that behavior (Chang, 2004; Stormshak et al., 1999; Torrente, Cappella, \& Neal, 2014). This norm may be defined as the extent to which behaviors occur in the classroom. The descriptive norm for prosocial behavior is, for example, the overall level of prosocial behavior shown by all students in a classroom together. The studies examining the moderating role of classroom descriptive norms in the association between student behavior and social status in early adolescence are limited in scope for two reasons. First, they have focused mostly on social preference as a measure of social status (see, for an exception, Garandeau, Ahn, \& Rodkin, 2011). Social preference refers to the liking of students by their classmates (Cillessen \& Marks, 2011). However, students' visibility and power in the classroom, that is their popularity, is also a highly relevant form of social status in early adolescence (e.g., Cillessen \& Marks, 2011; Mayeux, Houser, \& Dyches, 2011). Second, studies examining classroom descriptive norms in early adolescence have primarily focused on bullying behavior (e.g., Dijkstra, Lindenberg, \& Veenstra, 2008; Sentse, Scholte, Salmivalli, \& Voeten, 2007; Sentse, Veenstra, Kiuru, \& Salmivalli, 2015). The effects of classroom norms on other behaviors related to social status have largely been ignored in early adolescence. Given these gaps in the literature, the present study addressed the moderating effects of classroom norms on the associations of student behavior with both social preference and popularity in an early adolescent sample.

\section{Student Behavior and Social Status}

Social preference and popularity are two types of social status that are only moderately associated in early adolescence (Cillessen \& Mayeux, 2004). The 
similarities and differences between the two types of social status are shown by the student behaviors that are related to them. Newcomb et al. (1993) classified the behaviors associated with peer social status in four categories: prosocial behavior, social withdrawal, aggression, and academic reputation. Prosocial behavior and social withdrawal relate in a similar way to both social preference and popularity (Asher \& McDonald, 2009; LaFontana \& Cillessen, 2002; Lease et al., 2002; Newcomb et al., 1993). Students who cooperate with their classmates and help others are more accepted and popular than students who do not act prosocially. Likewise, students who withdraw from interactions with peers typically are less accepted and less popular than students who are not withdrawn.

The associations of aggression and academic reputation with social preference differ from the associations between these behaviors and popularity (Asher \& McDonald, 2009; LaFontana \& Cillessen, 2002; Lease et al., 2002; Newcomb et al., 1993). Students who show aggression are often rejected by their peers, but aggression is unrelated or even positively associated with popularity (Cillessen \& Mayeux, 2004; Rose, Swenson, \& Waller, 2004; Vaillancourt \& Hymel, 2006). Also, students who do well academically are more accepted than students who do less well (Wentzel, 2009). Yet, the direction of the association between academic reputation and popularity is less clear, as studies have found mixed results ranging from positive to negative (e.g., Boyatzis, Baloff, \& Durieux, 1998; LaFontana \& Cillessen, 2002; Schwartz, Gorman, Nakamoto, \& McKay, 2006).

\section{Classroom Norms and Social Status}

Previous studies have shown that both the strength and the direction of the behavior-status association may vary between classrooms (e.g., Chang, 2004; Meisinger, Blake, Lease, Palardy, \& Olejnik, 2007; Stormshak et al., 1999; Torrente et al., 2014). Descriptive norms may be a key element of the classroom context explaining these variations (Asher \& McDonald, 2009). Contrary to injunctive norms that are based on students' beliefs of how one should behave, descriptive norms are based on judgments of how students actually behave in the classroom (Henry et al., 2000).

Two types of models provide a framework for understanding the role of group norms in behavior-status associations. The first type of model assumes that the more consistent the behavior of a student is with the group norm, the higher her or his status will be in that group. In this model, both the strength and the direction of the behavior-status association may vary between classrooms. For example, in a classic study of 10-year-old boys with emotional and behavioral problems at a summer camp, aggressive boys were rejected by their peers in low-aggressive groups, whereas they were accepted in high-aggressive 
groups (Wright, Giammarino, \& Parad, 1986). This type of model has been referred to as the individual-group similarity model (Wright et al., 1986) or the social context model (Chang, 2004). The second type of model assumes that some behaviors (e.g., prosociality) are social skills that are necessary to be accepted among peers regardless of the context. That is, the strength of the behavior-status association may vary between classrooms, but the direction will not. This type of model has been referred to as the social skills model (Boivin, Dodge, \& Coie, 1995; Stormshak et al., 1999).

For social preference, both models have been tested with children and adolescents from different backgrounds in several settings (i.e., classroom, summer camp, laboratory playgroup; Boivin et al., 1995; Chang, 2004; Chen, Chang, \& He, 2003; Stormshak et al., 1999; Torrente et al., 2014; Wright et al., 1986). The studies focusing on descriptive norms in the classroom have shown that the associations of aggression and social withdrawal with social preference follow the individual-group similarity model. Stormshak et al. (1999) showed, in a representative sample of first-grade U.S. classrooms, that aggression was negatively related to peer acceptance in classrooms where aggressive behavior was non-normative. However, aggression was not related to social preference in classrooms where aggressive behavior was the norm. Similarly, they found that social withdrawal was negatively associated with social preference in classrooms in which it was non-normative, whereas it was not associated with social preference when it was normative. Chang (2004) replicated these findings for aggression and social withdrawal in seventh- to ninth-grade Chinese classrooms. However, in a recent study on aggression and social status among fourth- and fifth-grade U.S. classrooms, the classroom descriptive norm did not moderate the aggression-social preference association (Garandeau et al., 2011). The lack of effect of the classroom descriptive norm in this study may be explained by the fact that several other classroom-level variables were included as predictors at the same time (hierarchy, classroom academic level, grade level, and ethnic composition). These other variables (especially status hierarchy) then explained the variance in the aggression-social preference association. Thus, in this particular study, there was no effect of classroom norms when other classroom-level characteristics were included as predictors at the same time.

The effect of the classroom descriptive norm for prosocial behavior tends to be more in line with the social skills model. In other words, prosocial behavior usually is positively associated with social preference in all classrooms. Studies are, however, inconclusive about whether the descriptive norm moderates the magnitude of this association. Chang (2004) and Torrente et al. (2014) in a sample of second- to fourth-grade urban African American classrooms found that the magnitude of the association between prosocial 
behavior and social preference was enhanced when prosociality was more normative in the classroom. However, Stormshak et al. (1999) found the association to be independent of the classroom norm.

For academic reputation, it is less clear which of the two models best describes the role of the classroom norm as this has hardly been studied. The individual-group similarity model seems to fit best, as smart students may be liked in some classrooms (e.g., because they are great to work with) whereas they may be disliked in other classrooms students (e.g., because they are seen as know-it-alls). Consistent with this reasoning, Torrente et al. (2014) found that in classrooms with higher academic norms, the positive association between doing well academically and social preference was stronger. Based on this finding, they concluded that the association between academic reputation and social preference was in line with the individual-group similarity model.

For popularity, the role of classroom norms has rarely been investigated. This is surprising, because popularity is a group phenomenon (Rubin et al., 2006), and it is therefore likely that the context contributes to popularity. Meisinger et al. (2007) examined whether multiple predictors of popularity, such as excluding others (aggression), social withdrawal, prosocial behavior, and brightness (academic reputation) varied between fourth- to sixth-grade U.S. classrooms that differed in ethnic composition. The positive association between excluding others and popularity was stronger in Black majority classrooms than in White majority classrooms, but the other behaviors were invariant predictors of popularity across classrooms. Furthermore, Garandeau et al. (2011) found that classroom levels of aggressive behavior did not moderate the aggression-popularity association after controlling for other classroom-level variables. Thus, classroom norms may be less influential in the associations between behavior and popularity than in the associations between behavior and social preference.

In addition, the direction of the behavior-status associations may also vary between the two types of social status. Whereas behaving consistently with the classroom norm may help students to be accepted by peers, behaving inconsistently with classroom norms (i.e., being unique or deviant) may make students popular. This idea was supported by a study of group norms and social dominance in seventh-grade German classrooms. The study showed that the association between disruptive behavior and social dominance was stronger in classrooms where disruptive behavior was less normative (Jonkmann, Trautwein, \& Lüdtke, 2009). In those classrooms, disruptive behavior made students highly visible, which led to high social dominance. Because visibility is relevant for social dominance and popularity (Lease et al., 2002), behaving inconsistently rather than consistently with the classroom norm may contribute to students' popularity. 


\section{The Present Study}

The aim of this study was to examine the moderating role of classroom descriptive norms in the associations of the four categories of behavior with social status. In order to compare the effects of norms on both types of social status, social preference and popularity were examined. We examined early adolescents (age 10-12), whereas previous studies on classroom descriptive norms for these behaviors have examined middle childhood (Stormshak et al., 1999; Torrente et al., 2014) or middle adolescence (Chang, 2004). Early adolescence is a unique developmental period with many biological, cognitive, and social changes (Steinberg, 2013). One such change is that students start caring less about the norms of adults and more about conforming to peer norms (Masten, Juvonen, \& Spatzier, 2009; Rubin et al., 2006). In many school systems, early adolescents spend most of their day with the same peers in the same classroom. Therefore, classroom descriptive norms may be particularly relevant at this time. In middle and late adolescence, students attend multiple classes each day and encounter a larger variety of peer groups. Although peer norms continue to be important, classroom norms may then be less important than in early adolescence.

Based on two theoretical models (the social skills model, Stormshak et al., 1999; and the individual-group similarity model, Wright et al., 1986) and on previous work (Chang, 2004; Stormshak et al., 1999; Torrente et al., 2014), the following hypotheses guided this study. In line with the individual-group similarity model, we hypothesized that the negative associations of aggression and withdrawal with social preference would be weaker when each behavior was more consistent with the classroom norm. Based on the social skills model, we expected that the positive association between prosocial behavior and social preference would be invariant across classrooms. In line with an individual-group similarity model, we expected that the positive association of academic reputation with social preference would be stronger in classrooms in which it was the norm to do well academically. In addition, based on the individual-group similarity model and Jonkmann et al. (2009), we expected a positive association between aggression and popularity that would be stronger in classrooms with a lower aggression norm. In line with the social skills model and Meisinger et al. (2007), we expected negative associations of social withdrawal and positive associations of prosocial behavior and academic reputation with popularity regardless of classroom norms.

Previous studies on the moderating role of group norms for aggression did not distinguish overt aggression (kicking, hitting, name calling) from relational aggression (gossip, exclusion). Yet, aggression-status associations depend on the form of aggression. For example, the positive association between aggression 
and popularity is weaker for overt than for relational aggression (Rose et al., 2004). Therefore, we examined overt and relational aggression separately.

Finally, we included gender because of moderate but consistent gender differences in student behavior (e.g., girls scoring higher on prosocial behavior and lower on overt aggression than boys, cf. Rose \& Rudolph, 2006). Given previous findings, we also included moderation by gender of behavior-status associations. Previous research has found, for example, more pronounced associations between relational aggression and social status for girls than for boys (e.g., Cillessen \& Mayeux, 2004; Rose et al., 2004; Vaillancourt \& Hymel, 2006) and weaker associations of prosocial behavior and academic reputation with social preference for girls than for boys (Torrente et al., 2014).

\section{Method}

\section{Participants}

Participants came from 59 fifth-grade classrooms of 41 elementary schools in the Netherlands. The schools were equally divided between (semi-) urban $(51.2 \%)$ and rural areas (48.8\%). Schools ranged in size from 151 to 610 students. Average classroom size was 26.4 students $(S D=4.2$, range $=18-42)$. Of the 1,560 students in these classrooms, 1,492 (95.6\%) had active parental permission for participation and were present at data collection $\left(\bar{X}_{\text {age }}=10.6\right.$ years, $S D=0.5$ years, $53 \%$ boys $), 46(2.9 \%)$ had active parental consent but were absent on the day of data collection, and $22(1.4 \%)$ were not allowed to participate. Ethnic background was based on parental background and followed the classification by Statistics Netherlands (2012b): both parents born in the Netherlands (83.4\%), at least one parent born in another Western country $(5.6 \%)$, one parent born in a non-western country $(10.9 \%)$, and ethnic background unknown $(0.1 \%)$. This distribution was representative for the areas in which the schools were located (Statistics Netherlands, 2012a).

\section{Procedure}

The data used in this study were part of a larger study on social status and classroom social climate in primary education. After a school's principal and fifth-grade teacher(s) granted permission for participation, a letter that explained the study and included a consent form was sent home with the students. Only students with parental consent could participate in the study. Data were collected in the fall semester.

Data collection took place during regular classroom hours with the teacher present in the classroom. After the instruction, in which the researcher emphasized the confidentiality of the answers, students completed sociometric 
questions on a netbook computer. To further enhance confidentiality, students were seated individually, and partitioning screens were placed on both sides of their netbook so that they could not see the computer screen of their peers. During assessment, the researcher was available to assist students who requested help.

Unlimited same-sex and cross-sex nominations were allowed for each question. Students were asked to nominate at least one peer for each question. Students could not nominate themselves. Students could choose any student in their classroom (including students who were absent or did not consent to participate), but nominations for non-consented students were removed after data collection. Thus, the variables and analyses included data about all consented students (both present and absent). The classroom was the reference group (rather than the grade) because these students spent most of their time at school with the same peers in the same classroom. The procedure was approved by the Institutional Review Board of our institution.

\section{Measures}

Student behavior and social status. Students completed peer nominations of classmates who they thought "cooperate well," "help others," "call names," "kick, hit, or push," "gossip," "exclude others," "play or sit alone during breaks," and "get good grades." They also nominated classmates whom they "liked most," "liked least," and thought were "most popular" and "least popular." For each student, nominations received were summed for each item and divided by the total number of nominators in that classroom to create a proportion score for each item.

For overt aggression, an average score was computed from the proportion scores for "calls names" and "kicks, hits, or pushes" $(r=.92)$. Relational aggression was the average of the proportion scores for "gossips" and "excludes others" $(r=.70)$. Social withdrawal was measured with the item "plays or sits alone during breaks." For prosocial behavior, an average score was computed from the proportion scores for "cooperates well" and "helps others" $(r=.75)$. Academic reputation was measured with the item "gets good grades."

For social preference, the proportion of nominations received for "liked least" was subtracted from the proportion of nominations received for "liked most." A score for popularity was determined by subtracting the proportion of nominations received for "least popular" from the proportion of nominations received for "most popular."

Classroom descriptive norms. In line with recent studies (e.g., Garandeau et al., 2011; Sentse et al., 2007; Sentse et al., 2015; Torrente et al., 2014), classroom 
descriptive norms were computed by averaging the individual proportion scores of all students in the classroom. For the overt aggression norm ("calls names" and "kicks, hits, or pushes"), relational aggression norm ("gossips" and "excludes others"), and prosocial norm ("cooperates well" and "helps others"), the average of two norms was taken. The norms for social withdrawal and academic reputation were based on the respective single items.

\section{Analysis Strategy}

Multilevel models were run to test predictors at two levels (student and classroom) and cross-level interactions. All predictors at Level 1 (student) and Level 2 (classroom) were centered except for gender $(0=$ boys, $1=$ girls $)$. As recommended by Enders and Tofighi (2007), Level 1 (student) predictors were centered at the group mean (i.e., within each classroom), and Level 2 (classroom) predictors were centered at the grand mean (across all classrooms). Group mean centering Level 1 (student) predictors leads to more accurate estimates of the within-classroom slope because all variation due to differences between classrooms is removed. Group mean centering of the Level 1 (student) predictors is necessary when estimating cross-level interactions to obtain correct conclusions about them (Enders \& Tofighi, 2007). Grand mean centering of Level 2 (classroom) predictors facilitates the interpretation of these effects. The presented coefficients refer to classrooms with average levels of classroom norms. Because the gender of one student was unknown, the multilevel analyses were run with 1,537 students.

We ran several models to test the hypotheses. All models were run separately for social preference and popularity. First, we estimated an unconditional model, which allowed us to decompose the variance into within-classroom variance and between-classroom variance. Second, we ran a conditional model with the Level 1 predictors (gender, overt aggression, relational aggression, social withdrawal, prosocial behavior, and academic reputation) to test the effects of student behavior on social status (Model 1). Third, we entered the interaction terms between gender and student behavior to examine the possible moderating role of gender (Model 2). Statistically significant interaction effects were probed with simple slopes analysis (see Preacher, Curran, \& Bauer, 2006). Fourth, we added random slopes to test whether the associations between student behavior and social status varied between classrooms. Fifth, we added the Level 2 predictors (classroom norms for all behaviors) and cross-level interactions between each behavior and the corresponding classroom norm. To understand the statistically significant cross-level interactions, we plotted them using Preacher et al.'s (2006) procedure. Each norm was tested in a separate model (Models 3a-3e) because 
popularity models would not converge when adding all effects simultaneously. As our interest was mainly in the cross-level interactions, the "Results" section focuses on those effects.

Multilevel analyses were run in R v 3.1.2 (R Core Team, 2014) using the nlme package v 3.1-117 with the "optim" optimizer (Pinheiro, Bates, DebRoy, Sarkar, \& R Core Team, 2014). In order to compare models with deviance tests, we used full instead of restricted maximum likelihood estimation (Hox, 2002). We used the deviance test to determine model fit. When deviance tests were not statistically significant, the most parsimonious model was kept.

\section{Results}

\section{Descriptive Statistics and Correlations}

Table 1 shows means and $S D$ s for all variables at Level 1 (individual) and Level 2 (classroom) and the Level 1 variables for boys and girls separately. Table 2 shows the bivariate correlations among the study variables at both levels. At the individual level, all variables were weakly to strongly associated in the expected direction, with the exception of overt aggression and social withdrawal, which were not significantly associated. At the classroom level, there were positive associations among the norms for overt aggression, relational aggression, prosocial behavior, and academic reputation. There was a positive association between the norms for prosocial behavior and social withdrawal. None of the other norms were associated with the norm for social withdrawal. The fact that all significant associations between norms were positive might reflect a general tendency for students to name more peers in some classrooms than in other classrooms (e.g., because in some classrooms, students may have attended more to the behavior of their peers than in other classrooms). However, associations among related constructs (e.g., overt and relational aggression) were higher than associations among less related constructs (e.g., overt aggression and academic reputation).

\section{Models Predicting Social Preference}

Unconditional model. The unconditional model yielded an Intraclass Correlation Coefficient (ICC) of .0028 , indicating that $0.3 \%$ of the variation in students' social preference was due to differences between classrooms and $99.7 \%$ was due to differences between students within classrooms.

Level I models. The conditional models for social preference with the unstandardized estimates and standard errors for the fixed effects, the Level 1 and 2 variances, and the deviance statistics are presented in Table 3. The first conditional 
Table I. Means and Standard Deviations for the Total Sample and by Gender (Uncorrected for Classroom-Level Differences).

\begin{tabular}{|c|c|c|c|c|c|c|}
\hline \multirow[b]{2}{*}{ Variable } & \multicolumn{2}{|c|}{ Total $^{\mathrm{a}}$} & \multicolumn{2}{|c|}{ Boys $^{b}$} & \multicolumn{2}{|c|}{ Girlsc } \\
\hline & $\bar{X}$ & $S D$ & $\bar{X}$ & $S D$ & $\bar{X}$ & $S D$ \\
\hline \multicolumn{7}{|l|}{ Individual level (Level I) } \\
\hline Overt aggression & 0.12 & 0.18 & 0.19 & 0.21 & 0.04 & 0.07 \\
\hline Relational aggression & 0.13 & 0.13 & 0.12 & 0.12 & 0.13 & 0.14 \\
\hline Social withdrawal & 0.07 & 0.12 & 0.07 & 0.12 & 0.07 & 0.12 \\
\hline Prosocial behavior & 0.27 & 0.15 & 0.22 & 0.14 & 0.32 & 0.15 \\
\hline Academic reputation & 0.25 & 0.24 & 0.26 & 0.25 & 0.23 & 0.22 \\
\hline Social preference & 0.04 & 0.18 & 0.01 & 0.20 & 0.08 & 0.16 \\
\hline Popularity & -0.02 & 0.30 & 0.00 & 0.31 & -0.04 & 0.28 \\
\hline \multicolumn{7}{|l|}{ Classroom level (Level 2) } \\
\hline Overt aggression norm & 0.12 & 0.05 & & & & \\
\hline Relational aggression norm & 0.13 & 0.04 & & & & \\
\hline Social withdrawal norm & 0.07 & 0.03 & & & & \\
\hline Prosocial behavior norm & 0.27 & 0.07 & & & & \\
\hline Academic reputation norm & 0.25 & 0.06 & & & & \\
\hline
\end{tabular}

Note. ${ }^{a}$ At Level I $n=1,538$, at Level $2 n=59$.

$b_{n}=813$.

$c_{n}=724$.

Table 2. Bivariate Correlations Among the Study Variables (Uncorrected for Classroom-Level Differences).

\begin{tabular}{lccccccc}
\hline & 1 & 2 & 3 & 4 & 5 & 6 & 7 \\
\hline I. Overt aggression & - & $.70^{* *}$ & .23 & $.26 *$ & $.37^{* *}$ & & \\
2. Relational aggression & $.58^{* *}$ & - & .25 & $.27^{*}$ & $.34^{*}$ & \\
3. Social withdrawal & .03 & $-.11^{* *}$ & - & $.36^{*}$ & .14 & \\
4. Prosocial behavior & $-.44^{* *}$ & $-.24 * *$ & $-.18^{* *}$ & - & $.60^{* *}$ & \\
5. Academic reputation & $-.17^{* *}$ & $-.13^{* *}$ & $-.12^{* *}$ & $.53^{* *}$ & - & & \\
6. Social preference & $-.58^{* *}$ & $-.39 * *$ & $-.34^{* *}$ & $.63^{* *}$ & $.32^{* *}$ & - & \\
7. Popularity & $.12^{* *}$ & $.35^{* *}$ & $-.53^{* *}$ & $.23^{* *}$ & $.20^{* *}$ & $.37^{* *}$ & - \\
\hline
\end{tabular}

Note. Level I correlations (individual behavior) are shown below the diagonal. Level 2 correlations (classroom norms) are presented above the diagonal.

${ }^{*} p<.05 .{ }^{* *} p<.01$.

model (Model 1) significantly improved model fit over the unconditional model, $\chi_{\text {dif }}^{2}(6)=1,423.73, p<.001$. Together, the individual predictors explained $61.86 \%$ of the Level 1 variance in social preference. Boys were accepted more 


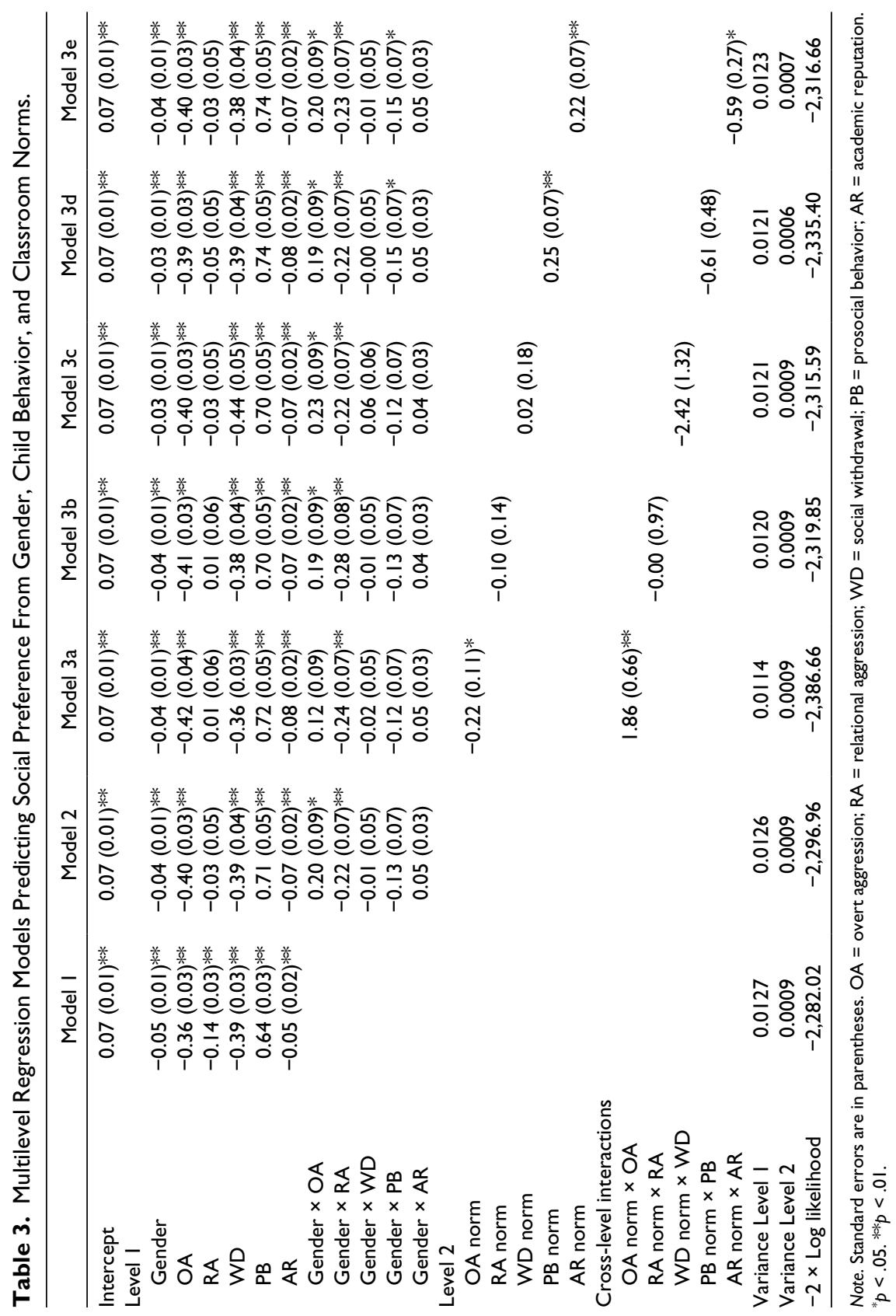


Table 4. Variance Components of Level I Regression Slopes for Social Preference and Popularity and Variance Explained by Classroom Norms.

\begin{tabular}{|c|c|c|c|c|}
\hline \multirow[b]{2}{*}{ Random slope } & \multicolumn{2}{|c|}{ Original random slope variance } & \multicolumn{2}{|c|}{ Model 3 variance } \\
\hline & Component & $\chi_{\text {dif }}^{2}(2)$ & Component & $\chi_{\text {dif }}^{2}(2)$ \\
\hline \multicolumn{5}{|l|}{ Social preference } \\
\hline Overt aggression & 0.0409 & $77.06 * *$ & 0.0336 & $12.63^{* *}$ \\
\hline Relational aggression & 0.0389 & $22.38 * *$ & 0.0387 & 0.49 \\
\hline Social withdrawal & 0.0355 & $15.30 * *$ & 0.0325 & 3.32 \\
\hline Prosocial behavior & 0.0310 & $22.32 * *$ & 0.0294 & $16.11 * *$ \\
\hline Academic reputation & 0.0056 & $6.78 *$ & 0.0048 & $|2.9| * *$ \\
\hline \multicolumn{5}{|l|}{ Popularity } \\
\hline Overt aggression & 0.1217 & $48.17^{* *}$ & 0.1059 & 4.77 \\
\hline Relational aggression & 0.0213 & $47.96 * *$ & 0.0213 & 0.71 \\
\hline Social withdrawal & 0.0471 & 3.68 & - & - \\
\hline Prosocial behavior & 0.0203 & $56.52 * *$ & 0.0204 & 0.09 \\
\hline Academic reputation & 0.0492 & $32.26 * *$ & 0.0473 & 3.64 \\
\hline
\end{tabular}

than girls after controlling for all other predictors. Overt aggression, relational aggression, social withdrawal, and academic reputation were negatively associated with social preference, and prosocial behavior was positively associated with social preference (net all other predictors).

In Model 2, the interactions of student behavior with gender were added. This significantly improved model fit, $\chi_{\text {dif }}^{2}(5)=14.95, p=.01$. However, the additional variance explained at Level 1 was only $0.36 \%$. In this model, relational aggression no longer predicted social preference. This association and the association between overt aggression and social preference were moderated by gender. The follow-up analyses showed that the negative association between overt aggression and social preference was stronger for boys $(b=$ $-0.40, S E=0.03, t=-12.23, p<.001)$ than for girls $(b=-0.20, S E=0.08$, $t=-2.56, p=.01)$. Relational aggression was negatively associated with social preference for girls $(b=-0.25, S E=0.04, t=-5.66, p<.001)$ but not for boys $(b=-0.03, S E=0.05, t=-0.52, p=.61)$.

Cross-level interaction models. Before we added the cross-level interactions, we checked whether the association between student behavior and social preference varied across classrooms. Table 4 gives the variances of the random slopes before (original variance component) and after the inclusion of each classroom norm (Model 3 variance component) as well as the improvement in 


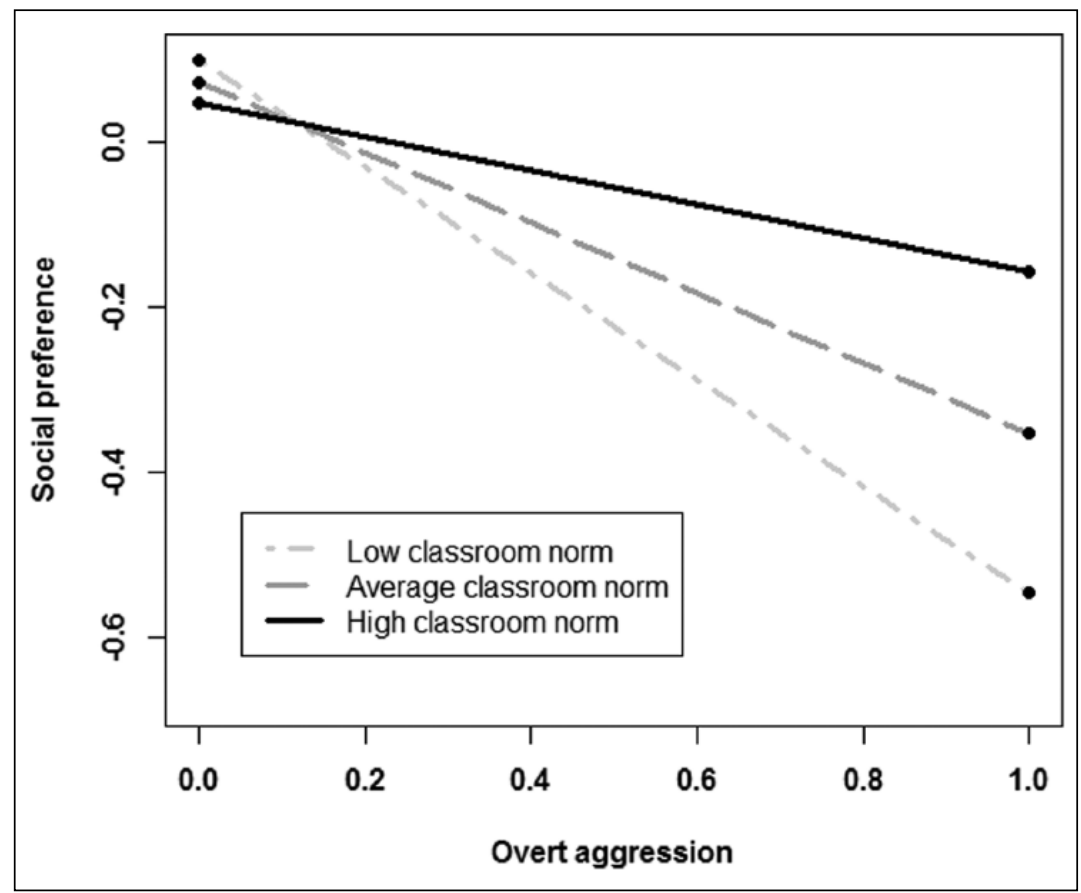

Figure I. Regression of overt aggression predicting social preference for classrooms with low (-ISD), average, and high (+I SD) norms for overt aggression.

model fit. All original slope variances were statistically significant. Therefore, we ran five models in which we entered each Level 2 classroom norm and corresponding cross-level interaction (Table 3, Models 3a-3e).

Model 3a, the model for overt aggression, explained an additional $3.72 \%$ of the Level 1 variance. The Level 1 (student) effect of overt aggression indicated that in a classroom with average levels of overt aggression, a 0.10 increase in the proportion score for overt aggression of a student was associated with a 0.042 (i.e., $-.42 / 10$ ) decrease in the proportion score for social preference for this student after controlling for all other predictors. The Level 2 (classroom) effect of overt aggression indicated that a 0.10 increase of the classroom norm for overt aggression was associated with a $0.022(-.22 / 10)$ decrease in the proportion score for social preference for all students in the classroom. The significant cross-level interaction indicated that the classroom norm for overt aggression moderated the association of overt aggression with social preference. Figure 1 shows that the negative association between overt aggression and social preference was attenuated in classrooms 
with higher norms for overt aggression. The classroom norm for overt aggression explained $17.90 \%$ of the variation between classrooms in the association between overt aggression and social preference.

The inclusion of the random slopes for relational aggression and social withdrawal both significantly improved model fit, but the inclusion of these norms did not explain additional variance in their respective models (Table 3, Models $3 \mathrm{~b}$ and $3 \mathrm{c}$ ). In other words, although the association of relational aggression and social withdrawal with social preference varied between classrooms, this variation has to be explained by other factors than classroom norms.

Model 3d shows that combined inclusion of a random slope, prosocial norm, and cross-level interaction explained an additional $1.66 \%$ of the Level 1 variance. The cross-level interaction was not significant, indicating that the betweenclassroom variation in the association between prosocial behavior and social preference did not depend on the classroom norm for prosocial behavior.

Finally, Model 3e, for academic reputation, explained $0.91 \%$ of the Level 1 variance. The classroom norm for academic reputation moderated the association between individual academic reputation and social preference and explained $14.89 \%$ of the between-classroom variance in this association. Figure 2 shows that the negative association between academic reputation and social preference was enhanced in classrooms with higher norms for academic reputation.

\section{Models Predicting Popularity}

Unconditional model. The unconditional model showed that the ICC was smaller than .0001 . Thus, all variability in popularity was due to individual differences.

Level I models. The conditional models for popularity are presented in Table 5. Model 1 fit better than the unconditional model, $\chi_{\text {dif }}^{2}(6)=1,022.35, p<.001$, and explained $48.58 \%$ of the Level 1 variance in popularity. Girls were less popular than boys. Relational aggression and prosocial behavior were positively associated with popularity. Social withdrawal was negatively associated with popularity. Overt aggression and academic reputation were unrelated to popularity.

In Model 2, we tested whether the effects found in Model 1 could be further explained by students' gender. Including the gender interaction terms significantly improved model fit, $\chi_{\text {dif }}^{2}(5)=28.79, p<.001$. However, just as with social preference, the additional variance explained was small $(0.96 \%)$. In addition to the main effects that were found in Model 1, the main effect of overt aggression as well as the interaction effects of overt aggression, relational aggression, and academic reputation with gender were significant. The follow-up analyses showed that overt aggression was negatively associated with popularity for boys $(b=-0.17, S E=0.06, t=-2.74, p=.006)$, but not 


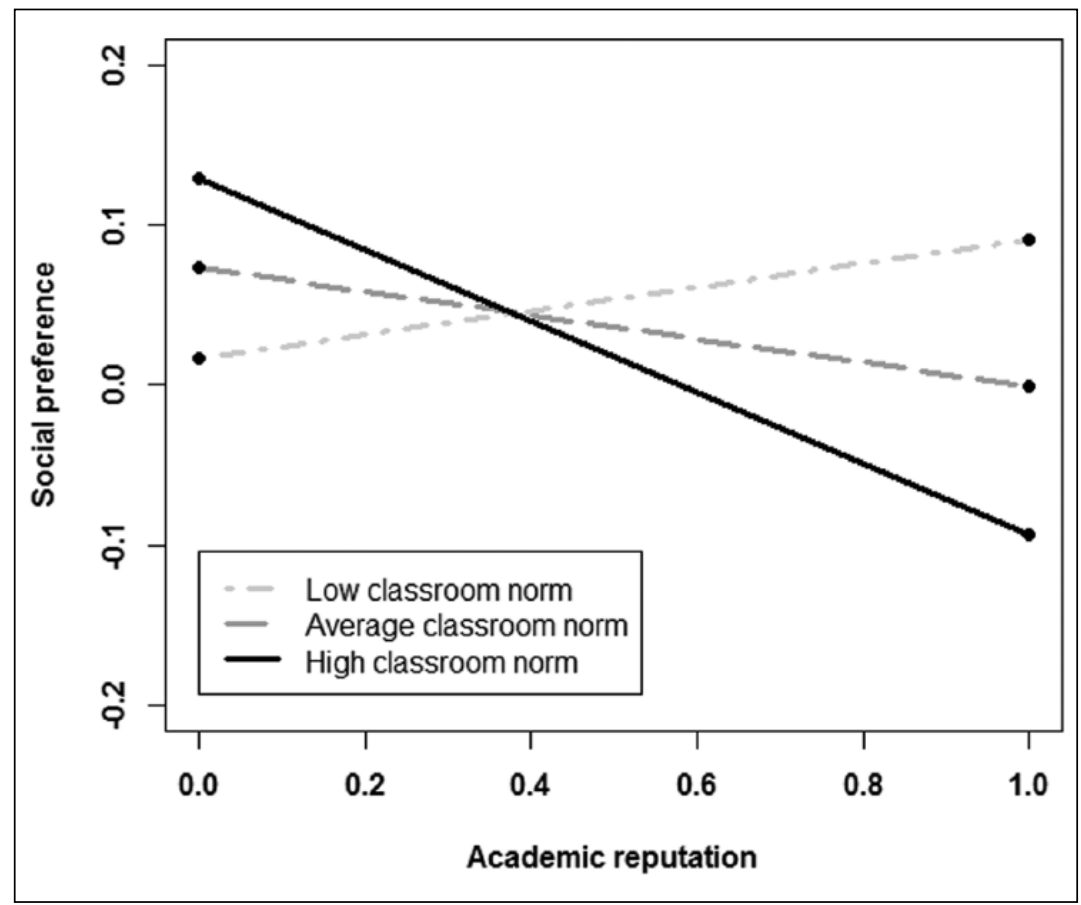

Figure 2. Regression of academic reputation predicting social preference for classrooms with low (-ISD), average, and high (+ISD) norms for academic reputation.

for girls $(b=0.21, S E=0.14, t=1.48, p=.14)$. Relational aggression was positively associated with popularity for both genders, but the effect was stronger for boys $(b=1.40, S E=0.10, t=14.65, p<.001)$ than for girls $(b=$ $0.87, S E=0.08, t=10.83, p<.001)$. The model also showed an interaction between gender and academic reputation. However, academic reputation was unrelated to popularity for boys $(b=-0.06, S E=0.04, t=-1.60, p=.11)$ and for girls $(b=0.06, S E=.05, t=1.28, p=0.20)$.

Cross-level interaction models. Before we ran the cross-level models, we checked whether the slope between each behavior and popularity varied between classrooms. The random slope variation for social withdrawal was not significant (Table 4), indicating that the effect of withdrawal on popularity was invariant across classrooms. Therefore, we did not include a model with the classroom norm for social withdrawal. Thus, we tested four cross-level interaction models that are shown in Table 5 (Models 3a, 3b, 3d, and 3e). 


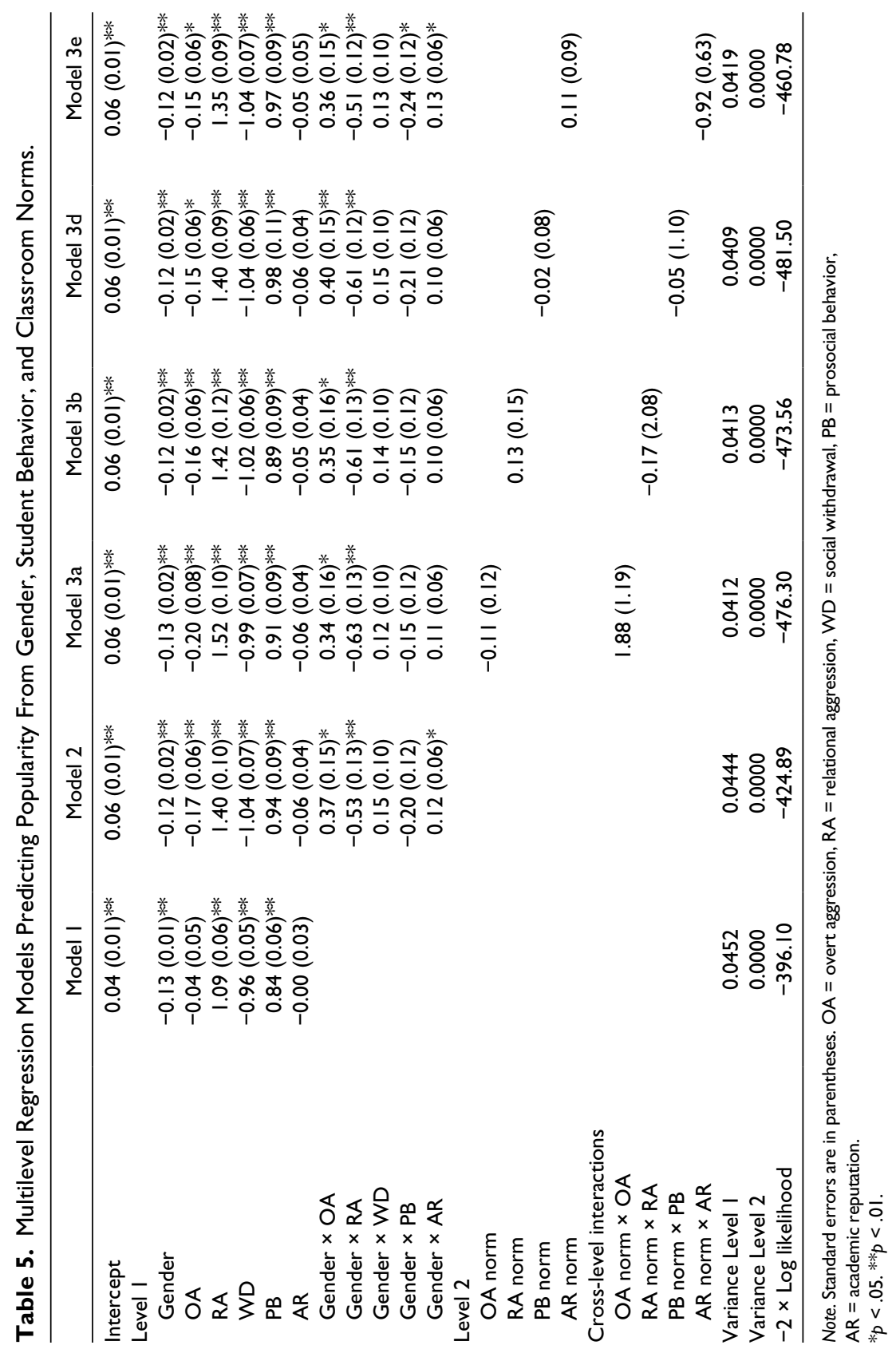


As can be seen in Table 5, including classroom norms for overt aggression (Model 3a), relational aggression (Model 3b), prosocial behavior (Model 3d), or academic reputation (Model 3e) did not improve model fit. The associations between these behaviors and popularity were not moderated by the classroom descriptive norms for each behavior.

\section{Discussion}

Classroom descriptive norms have been found to moderate the associations of aggression, social withdrawal, prosocial behavior, and academic reputation with social preference in middle childhood and mid-adolescence (Chang, 2004; Stormshak et al., 1999; Torrente et al., 2014). In the present study, we set out to replicate these findings in early adolescence. In addition, we examined the moderating effects of classroom norms in the associations of social behaviors with popularity. For social preference, the classroom norm for overt aggression attenuated the negative association between students' overt aggression and social preference. In other words, when classroom levels of overt aggression were higher, the negative association of overt aggression with social preference was weaker. This finding was in line with our expectations. Unexpectedly, the classroom norm for academic reputation enhanced the negative association between students' academic reputation and social preference. That is, when classroom levels of academic reputation were higher, the negative association of academic reputation with social preference was stronger. The strength and direction of the associations of relational aggression, social withdrawal, and prosocial behavior with social preference did not depend on the classroom norms. For relational aggression and social withdrawal, this finding ran against our hypotheses, whereas for prosocial behavior the finding was in line with our expectations. For popularity, interestingly, classroom descriptive norms did not moderate any of the behaviorpopularity associations. Although we expected this finding for most behaviors, it ran against our hypothesis for the association between aggression and popularity.

\section{Classroom Norms and Social Preference}

In line with our expectations and previous research (e.g., Chang, 2004; Stormshak et al., 1999), the negative association between overt aggression and social preference was weaker in classrooms where overt aggression was more normative. One explanation for this finding is that when there is more overt aggression in the classroom, this behavior is less useful as a criterion for students to decide who they like and do not like. The behavior is less 
unique and students showing it do not stand out. But in classrooms where it hardly occurs, overtly aggression clearly stands out in a negative way. Another explanation for this finding is that the higher the classroom norm for overt aggression, the more nominators in the classroom are overtly aggressive. As students tend to like others who are similar to them (Rubin et al., 2006), the more overtly aggressive students there are in a classroom, the more liking nominations overtly aggressive peers in the classroom will receive and the weaker the association between this behavior and social preference will be. It should be noted that, contrary to the individual-group similarity model (Wright et al., 1986), only the strength and not the direction of the association depended on the classroom norm. In all classrooms, overt aggression was negatively associated with social preference, which is in line with the social skills model (Stormshak et al., 1999). Yet the group levels of overt aggression were never very high (i.e., the highest proportion of students nominated as aggressive was .31). Overt aggression may become positively related to social preference only when group levels of aggression are high because the majority of the students are very aggressive (see, for example, Wright et al., 1986).

Contrary to our expectations, the classroom descriptive norm did not moderate the association between relational aggression and social preference. The absence of a moderating effect of classroom norms on the relational aggression-social preference association is in line with the social skills model (Stormshak et al., 1999). This effect is supported by a prospective study among Belgian third to fifth graders (Kuppens, Grietens, Onghena, Michiels, $\&$ Subramanian, 2008). In that study, peer rejection positively predicted relational aggression a year later regardless of the classroom descriptive norms for it. It may be that the association between relational aggression and social preference does not depend on the classroom norm because relational aggression is a more covert form of aggression and harder for students to detect than overt aggression. The contrasting findings between overt aggression and relational aggression highlight the importance of distinguishing between both forms of aggression, not only at the individual level but also at the classroom level.

Contrary to our hypothesis and findings in other age groups (Chang, 2004; Stormshak et al., 1999), the association between the social withdrawal and social preference was in line with the social skills model (Stormshak et al., 1999) and not with the individual-group similarity model (Wright et al., 1986). One explanation could be that peer interaction is so extremely important for early adolescents (Rubin et al., 2006) that they view social isolation in peers more negatively than younger and older students (Rubin \& Coplan, 2010) and are not very tolerant of it even when it occurs a lot in their classroom. Another 
explanation could be that the between-classroom variation in the norm was smaller in our sample than in the other studies (i.e., the $S D$ was .03 in our sample, whereas it was .22 in Chang's, 2004, sample). As a consequence, our study may have been less sensitive to detect effects of the classroom norm for social withdrawal. The reasons for differences in this variation remain speculative and might include differences in informants (peers vs. teachers in Stormshak et al., 1999), classroom size (50-60 students in Chang, 2004), and operationalizations of classroom norms (limited nominations and geometric mean scores in Chang, 2004).

In line with our expectations and previous research (Chang, 2004; Stormshak et al., 1999; Torrente et al., 2014), prosocial behavior was positively related to social preference regardless of group norms. This shows that prosocial behavior is a social skill that contributes to social preference regardless of context (Stormshak et al., 1999). In other words, students who are seen by classmates as not prosocial may not become highly accepted in any classroom context.

Although academic reputation and social preference were positively related, this association became negative after controlling for other factors. In line with our hypothesis, the association between academic reputation and social preference followed the individual-group similarity model (Wright et al., 1986). However, contrary to our expectations and previous research (Torrente et al., 2014), the negative association was stronger in classrooms where academic reputation was more normative. In other words, students were liked most by their peers if they were in high-achieving classrooms but were not seen as high achieving themselves. A tentative explanation for this finding may be that students in high-achieving classrooms, although they generally like each other, might also have some rivalry about who performs the best. Consequently, students who were not seen as rivals might, therefore, be liked better. This finding needs to be replicated, as the effect was small and other studies have found that the association between achievement and social preference was stronger in high-achieving cliques than in low-achieving cliques (Chen et al., 2003). Future research may also address whether the differences in findings were due to differences in grades, control variables (Torrente et al., 2014, did not include negative behaviors), or sample composition (e.g., with respect to ethnicity).

\section{Classroom Norms and Popularity}

This study included two types of social status. Contrary to social preference, the associations of student behavior with popularity were not moderated by classroom descriptive norms. This confirmed our hypotheses for social 
withdrawal, prosocial behavior, and academic reputation. However, it is at odds with our expectation that the association between aggression and popularity would be stronger in classrooms in which it was less normative (cf. Jonkmann et al., 2009). Our findings suggest that students who are prosocial and relationally aggressive according to peers (behaviors positively associated with popularity) will be popular in all contexts, regardless of prevailing norms.

That classroom norms did not moderate behavior-popularity associations but did moderate (some) behavior-social preference associations may be understood by the different way in which students judge both constructs. Social preference is a personal affective judgment of one other person ("who do you like") whereas popularity is the assessment of someone's reputation in the group at large ("who is popular?") irrespective of one's own personal feelings (Cillessen \& Marks, 2011). In their affective choices of classmates they personally like, students are inclined to choose peers who are similar to themselves. As a consequence, the extent to which a student is liked in the classroom depends both on her or his own individual characteristics as well as on those of the other students in the classroom. In reputational judgments, students have to set their personal feelings aside and give their observation of a peer's position in the entire group. In other words, peers are evaluated based on their individual characteristics only. Hence, there is more consensus among students about who is popular than about who is accepted (Marks, Babcock, Cillessen, \& Crick, 2013). Popularity also is more stable over time and across contexts than social preference (e.g., Cillessen \& Borch, 2006; Jiang \& Cillessen, 2005). Taken together, the results of this study and previous studies highlight the relevance of distinguishing social preference from popularity, especially in the adolescent peer group.

\section{Limitations}

The current study also had some limitations. First, we based classroom descriptive norms on the average proportion of nominations received in the classroom. Although this operationalization is commonly used, it does not capture all classroom-level differences in behavior. For example, the classroom norm is based on the proportion of students who show a certain behavior in the classroom but does not include the frequency and severity of the behavior (which also may impact the classroom norm). Also, by using the average proportion of nominations received, classrooms in which all students received some nomination may have had the same norm score as classrooms in which a few students received all nominations and the majority of the students received no nominations. However, the effect of the classroom norm on behavior-status associations might in fact differ between these classrooms 
(e.g., acting aggressively may have no consequences for the status of a student in a classroom in which everyone is seen as aggressive by some peers whereas it may have negative consequences for the status of a student in a classroom where he or she is one of the few who are seen as aggressive by everyone).

Second, all participants were Grade 5 students in Dutch elementary schools. Although the sample was representative for the Netherlands, classroom norms may play a different role in other school contexts or cultures. This is underlined by the fact that classroom norms for social withdrawal and academic reputation were differently related to social preference in our study than in studies conducted in China and the United States (Chang, 2004; Stormshak et al., 1999; Torrente et al., 2014).

Third, our study was cross-sectional. Because behavior, status, and norms were measured at the same time, it was not possible to relate norms to changes in behavior and status across the school year. This should be examined in future research, as the stability of social status was related to increases in verbal aggression in classrooms in which verbal aggression was more normative in one study (Bellmore, Villarreal, \& Ho, 2011).

\section{Future Directions for Research and Practical Implications}

There is still much to discover about the role of classroom context in the association between student behavior and social status. The random slopes in this study were statistically significant, indicating that the associations between student behavior and social status (both social preference and popularity) varied among classrooms. Yet the classroom descriptive norms did not explain all between-classroom variation. Therefore, a question for future research is what other factors might explain this variation. A potential moderator could be injunctive classroom norms. Whereas descriptive norms regard actual behavior in the classroom, injunctive norms describe how students think that classmates ought to behave in order to become popular (cf. Henry et al., 2000). For example, the association between relational aggression and popularity might be stronger in classrooms where students think that someone becomes popular by showing relational aggression than in classrooms where students do not hold such beliefs. Other potential contextual moderators of the behavior-status association that have been suggested include ethnic composition (Meisinger et al., 2007), classroom size (Chang, 2004), social network characteristics (Ahn, Garandeau, \& Rodkin, 2010; McCormick \& Cappella, 2015), status hierarchy (Garandeau et al., 2011), and teacher behavior (Mikami et al., 2010).

It could also be that the behavior of some students (e.g., those with high status) has more impact than the behavior of others. The norm-salience approach accounts 
for this idea by estimating the correlation between a certain behavior and social status (e.g., Henry et al., 2000). Norm salience scores and descriptive norms are distinct measures of the classroom context (e.g., Dijkstra \& Gest, 2015). The results of both measures may be compared to test whether the behavior of all students or of a few students are related to behavior-status associations.

Furthermore, it would also be possible to look at nominator effects, that is, the degree to which nominations are given by certain subgroups in the classroom or differ between subgroups (e.g., boys vs. girls, high-achieving vs. low-achieving students, popular vs. unpopular students). For example, a study of common and gender-specific classroom norms for victimization showed that same-sex classroom norms were associated with victimization, but general classroom norms were not (Isaacs, Voeten, \& Salmivalli, 2013).

The findings of this study show that students' social status does not solely depend on individual characteristics but also on the classroom context and the interaction between them. Therefore, we encourage practitioners to consider both individual and classroom characteristics when, for example, trying to increase the acceptance of students by their classmates. That said, individual characteristics explained much more variation in both forms of social status than classroom norms. This suggests that interventions to improve social status should not solely focus on the context but also on empowering the individual student.

\section{Conclusion}

The present study showed that the moderating role of classroom norms in the association between behavior and social status differed between social preference and popularity in early adolescence. Whereas associations of overt aggression and academic reputation with social preference depended on classroom descriptive norms, classroom norms did not moderate the associations between behavior and popularity. The findings also highlight the importance of studying classroom norms throughout development as some of our findings seemed unique for early adolescence.

\section{Declaration of Conflicting Interests}

The author(s) declared no potential conflicts of interest with respect to the research, authorship, and/or publication of this article.

\section{Funding}

The author(s) disclosed receipt of the following financial support for the research, authorship, and/or publication of this article: This research was funded by the Dutch Programme Council for Educational Research NWO-PROO Grant 411-10-915. 


\section{References}

Ahn, H., Garandeau, C. F., \& Rodkin, P. C. (2010). Effects of classroom embeddedness and density on the social status of aggressive and victimized children. Journal of Early Adolescence, 30, 76-101. doi:10.1177/0272431609350922

Asher, S. R., \& McDonald, K. L. (2009). The behavioral basis of acceptance, rejection, and perceived popularity. In K. H. Rubin, W. M. Bukowski, \& B. Laursen (Eds.), Handbook of peer interactions, relationships, and groups (pp. 232-248). New York, NY: Guilford.

Becker, B. E., \& Luthar, S. S. (2007). Peer-perceived admiration and social preference: Contextual correlates of positive peer regard among suburban and urban adolescents. Journal of Research on Adolescence, 17, 117-144. doi:10.1111/ j.1532-7795.2007.00514.x

Bellmore, A., Villarreal, V. M., \& Ho, A. Y. (2011). Staying cool across the first year of middle school. Journal of Youth and Adolescence, 40, 776-785. doi:10.1007/ s10964-010-9590-x

Boivin, M., Dodge, K. A., \& Coie, J. D. (1995). Individual-group behavioral similarity and peer status in experimental play groups of boys: The social misfit revisited. Journal of Personality and Social Psychology, 69, 269-279. doi:10.1037/00223514.69.2.269

Boyatzis, C. J., Baloff, P., \& Durieux, C. (1998). Effects of perceived attractiveness and academic success on early adolescent peer popularity. Journal of Genetic Psychology, 159, 337-344. doi:10.1080/00221329809596155

Chang, L. (2004). The role of classroom norms in contextualizing the relations of children's social behaviors to peer acceptance. Developmental Psychology, 40, 691-702. doi:10.1037/0012-1649.40.5.691

Chen, X., Chang, L., \& He, Y. (2003). The peer group as a context: Mediating and moderating effects on relations between academic achievement and social functioning in Chinese children. Child Development, 74, 710-727. doi:10.1111/14678624.00564

Cillessen, A. H. N., \& Borch, C. (2006). Developmental trajectories of adolescent popularity: A growth curve modelling analysis. Journal of Adolescence, 29, 935-959. doi:10.1016/j.adolescence.2006.05.005

Cillessen, A. H. N., \& Marks, P. E. L. (2011). Conceptualizing and measuring popularity. In A. H. N. Cillessen, D. Schwartz, \& L. Mayeux (Eds.), Popularity in the peer system (pp. 25-56). New York, NY: Guilford.

Cillessen, A. H. N., \& Mayeux, L. (2004). From censure to reinforcement: Developmental changes in the association between aggression and social status. Child Development, 75, 147-163. doi:10.1111/j.1467-8624.2004.00660.x

Dijkstra, J. K., \& Gest, S. D. (2015). Peer norm salience for academic achievement, prosocial behavior, and bullying: Implications for adolescent school experiences. Journal of Early Adolescence, 35, 79-96. doi:10.1177/0272431614524303

Dijkstra, J. K., Lindenberg, S. M., \& Veenstra, R. (2008). Beyond the class norm: Bullying behavior of popular adolescents and its relation to peer acceptance and rejection. Journal of Abnormal Child Psychology, 36, 1289-1299. doi:10.1007/ s10802-008-9251-7 
Enders, C. K., \& Tofighi, D. (2007). Centering predictor variables in cross-sectional multilevel models: A new look at an old issue. Psychological Methods, 12, 121-138. doi:10.1037/1082-989X.12.2.121

Garandeau, C. F., Ahn, H. J., \& Rodkin, P. C. (2011). The social status of aggressive students across contexts: The role of classroom status hierarchy, academic achievement, and grade. Developmental Psychology, 47, 1699-1710. doi:10.1037/a0025271

Henry, D., Guerra, N., Huesmann, R., Tolan, P., Van Acker, R., \& Eron, L. (2000). Normative influences on aggression in urban elementary school classrooms. American Journal of Community Psychology, 28, 59-81. doi:10.1023/A:1005142429725

Hox, J. J. (2002). Multilevel analyses: Techniques and applications. Mahwah, NJ: Lawrence Erlbaum.

Isaacs, J., Voeten, M., \& Salmivalli, C. (2013). Gender-specific or common classroom norms? Examining the contextual moderators of the risk for victimization. Social Development, 22, 555-579. doi:10.1111/j.1467-9507.2012.00655.x

Jiang, X. L., \& Cillessen, A. H. N. (2005). Stability of continuous measures of sociometric status: A meta-analysis. Developmental Review, 25, 1-25. doi:10.1016/j. dr.2004.08.008

Jonkmann, K., Trautwein, U., \& Lüdtke, O. (2009). Social dominance in adolescence: The moderating role of the classroom context and behavioral heterogeneity. Child Development, 80, 338-355. doi:10.1111/j.1467-8624.2009.01264.x

Kuppens, S., Grietens, H., Onghena, P., Michiels, D., \& Subramanian, S. V. (2008). Individual and classroom variables associated with relational aggression in elementary-school aged children: A multilevel analysis. Journal of School Psychology, 46, 639-660. doi:10.1016/j.jsp.2008.06.005

LaFontana, K. M., \& Cillessen, A. H. N. (2002). Children's perceptions of popular and unpopular peers: A multimethod assessment. Developmental Psychology, 38, 635-647. doi:10.1037/0012-1649.38.5.635

LaFontana, K. M., \& Cillessen, A. H. N. (2010). Developmental changes in the priority of perceived status in childhood and adolescence. Social Development, 19, 130-147. doi:10.1111/j.1467-9507.2008.00522.x

Lease, A. M., Musgrove, K. T., \& Axelrod, J. L. (2002). Dimensions of social status in preadolescent peer groups: Likability, perceived popularity, and social dominance. Social Development, 11, 508-533. doi:10.1111/1467-9507.00213

Marks, P. E. L., Babcock, B., Cillessen, A. H. N., \& Crick, N. R. (2013). The effects of participation rate on the internal reliability of peer nomination measures. Social Development, 22, 609-622. doi:10.1111/j.1467-9507.2012.00661.x

Masten, C. L., Juvonen, J., \& Spatzier, A. (2009). Relative importance of parents and peers: Differences in academic and social behaviors at three grade levels spanning late childhood and early adolescence. Journal of Early Adolescence, 29, 773-799. doi:10.1177/0272431608325504

Mayeux, L., Houser, J. J., \& Dyches, K. D. (2011). Social acceptance and popularity: Two distinct forms of peer status. In A. H. N. Cillessen, D. Schwartz, \& L. Mayeux (Eds.), Popularity in the peer system (pp. 79-102). New York, NY: Guilford. 
McCormick, M. P., \& Cappella, E. (2015). Conceptualizing academic norms in middle school: A social network perspective. Journal of Early Adolescence, 35, 441-466. doi:10.1177/0272431614535093

Meisinger, E. B., Blake, J. J., Lease, A. M., Palardy, G. J., \& Olejnik, S. F. (2007). Variant and invariant predictors of perceived popularity across majority-Black and majority-White classrooms. Journal of School Psychology, 45, 21-44. doi:10.1016/j.jsp.2006.09.005

Mikami, A. Y., Lerner, M. D., \& Lun, J. (2010). Social context influences on children's rejection by their peers. Child Development Perspectives, 4, 123-130. doi:10.1111/j.1750-8606.2010.00130.x

Newcomb, A. F., Bukoswki, W. M., \& Pattee, L. (1993). Children's peer relations: A meta-analytic review of popular, rejected, neglected, controversial, and average sociometric status. Psychological Bulletin, 113, 99-128. doi:10.1037/00332909.113.1.99

Pinheiro, J., Bates, D., DebRoy, S., Sarkar, D., \& R Core Team. (2014). nlme: Linear and nonlinear mixed effects models (Version 3.1-117) [Software]. Retrieved from http://CRAN.R-project.org/package $=$ nlme/

Preacher, K. J., Curran, P. J., \& Bauer, D. J. (2006). Computational tools for probing interactions in multiple linear regression, multilevel modeling, and latent curve analysis. Journal of Educational and Behavioral Statistics, 31, 437-448. doi:10.3102/10769986031004437

R Core Team. (2014). R: A language and environment for statistical computing (Version 3.1.1) [Software]. Retrieved from http://www.R-project.org/

Rose, A. J., \& Rudolph, K. D. (2006). A review of sex differences in peer relationship processes: Potential trade-offs for the emotional and behavioral development of girls and boys. Psychological Bulletin, 132, 98-131. doi:10.1037/00332909.132.1.98

Rose, A. J., Swenson, L. P., \& Waller, E. M. (2004). Overt and relational aggression and perceived popularity: Developmental differences in concurrent and prospective relations. Developmental Psychology, 40, 378-387. doi:10.1037/00121649.40.3.378

Rubin, K. H., Bukowski, W. M., \& Parker, J. G. (2006). Peer interactions, relationships, and groups. In N. Eisenberg (Ed.), Handbook of child psychology: Social, emotional, and personality development (6th ed., pp. 571-645). New York, NY: Wiley.

Rubin, K. H., \& Coplan, R. J. (2010). The development of shyness and social withdrawal. New York, NY: Guilford.

Schwartz, D., Gorman, A. H., Nakamoto, J., \& McKay, T. (2006). Popularity, social acceptance, and aggression in adolescent peer groups: Links with academic performance and school attendance. Developmental Psychology, 42, 1116-1127. doi:10.1037/0012-1649.42.6.1116

Sentse, M., Scholte, R., Salmivalli, C., \& Voeten, M. (2007). Person-group dissimilarity in involvement in bullying and its relation with social status. Journal of Abnormal Child Psychology, 35, 1009-1019. doi:10.1007/s10802-007-9150-3 
Sentse, M., Veenstra, R., Kiuru, N., \& Salmivalli, C. (2015). A longitudinal multilevel study of individual characteristics and classroom norms in explaining bullying behaviors. Journal of Abnormal Child Psychology, 43, 943-955. doi:10.1007/ s10802-014-9949-7

Statistics Netherlands. (2012a). Aandeel allochtonen per gemeente [Percentages immigrants by municipality]. Retrieved from http://www.cbs.nl/nl-NL/menu/ themas/dossiers/allochtonen/cijfers/extra/aandeel-allochtonen.htm

Statistics Netherlands. (2012b). Jaarrapport integratie 2012 [Annual report on integration 2012]. The Hague, The Netherlands: Centraal Bureau voor de Statistiek.

Steinberg, L. D. (2013). Adolescence. Boston, MA: McGraw-Hill.

Stormshak, E. A., Bierman, K. L., Bruschi, C., Dodge, K. A., Coie, J. D., \& The Conduct Problems Prevention Research Group. (1999). The relation between behavior problems and peer preference in different classroom contexts. Child Development, 70, 169-182. doi:10.1111/1467-8624.00013

Torrente, C. E., Cappella, E., \& Neal, J. W. (2014). Children's positive school behaviors and social preference in urban elementary classrooms. Journal of Community Psychology, 42, 143-161. doi:10.1002/jcop.21599

Vaillancourt, T., \& Hymel, S. (2006). Aggression and social status: The moderating roles of sex and peer-valued characteristics. Aggressive Behavior, 32, 396-408. doi:10.1002/ab.20138

Wentzel, K. R. (2009). Peers and academic functioning at school. In K. H. Rubin, W. M. Bukowski, \& B. Laursen (Eds.), Handbook of peer interactions, relationships, and groups (pp. 531-547). New York, NY: Guilford.

Wright, J. C., Giammarino, M., \& Parad, H. W. (1986). Social status in small groups: Individual-group similarity and the social "misfit." Journal of Personality and Social Psychology, 50, 523-536. doi:10.1037/0022-3514.50.3.523

\section{Author Biographies}

Henrike J. Boor-Klip is a $\mathrm{PhD}$ candidate in developmental psychology at Radboud University, Nijmegen, the Netherlands. Her research interests include social status, peer relationships, and classroom climate.

Eliane Segers is an associate professor at the learning and plasticity group of the Behavioural Science Institute at Radboud University, Nijmegen, the Netherlands. Her research interests include (individual differences in) learning, literacy, and numeracy, and social contexts of this learning.

Marloes M. H. G. Hendrickx is a $\mathrm{PhD}$ student in educational sciences at Utrecht University, the Netherlands. Her research focuses on the role of teacher-student relationships in shaping peer relationships and classroom climate.

Antonius H. N. Cillessen is a professor and chair of developmental psychology and director of the Behavioural Science Institute at Radboud University, Nijmegen, the Netherlands. His research interests include child and adolescent peer relationships and quantitative research methods for developmental psychology. 